\section{Conjunctival melanoma*}

Marilda Aparecida Milanez Morgado de $\mathrm{Abreu}^{1}$

Jéssica Priscila Tozo ${ }^{2}$

Amanda Kloster Wagner ${ }^{2}$

DOI: http:/ /dx.doi.org/10.1590/abd1806-4841.20187657

Dear Editor,

Melanoma is a cancer that has great importance due to its aggressive and invasive features of tissues and organs, being the main cause of death by skin-related diseases. It arises from melanocytes, skin cells responsible for the production of melanin mainly as a result of the ultraviolet radiation (UV). ${ }^{1}$

Ocular melanoma $(\mathrm{OM})$ is a primary intraocular malignant tumor, more common in adults. It is a primary neoplasm in the majority of cases but can occur as metastasis from a primary cutaneous site. It presents in two forms: uveal and conjunctival, the former being the most frequent. ${ }^{2}$

The uveal form is characterized by pigmented dendritic cells in a variable shape that are distributed in the iris's stroma, ciliary body and choroid. The conjunctival form has spindle-shaped and polyhedral pigmented epithelioid cells with the presence of intrusive and feeding vessels, commonly located in the bulbar conjunctiva. $^{2}$

Diagnosis is made with ophthalmoscopy and digital retinography but the confirmation is with histological analysis of the lesion. ${ }^{3}$

Treatment depends on the size of the tumor, of the presence of extraocular and/or systemic involvement, of the condition of the contralateral eye, of the patient's age, among other factors. ${ }^{3}$

A female 71-year-old Caucasian patient, housewife, had a lesion detected in the nasal conjunctiva of the right eye during a

Received 17 September 2017

Accepted 14 March 2018

* Work conducted at Hospital Regional de Presidente Prudente, Universidade do Oeste Paulista, Presidente Prudente (SP), Brazil.

Financial support: None.

Conflict of interest: None.

${ }^{1}$ Service of Dermatology, Hospital Regional de Presidente Prudente, Universidade do Oeste Paulista, Presidente Prudente (SP), Brazil.

2 Medical School student, Universidade do Oeste Paulista, Presidente Prudente (SP), Brazil.

MaILING AdDREss:

Jéssica Priscila Tozo

E-mail: jessicaptozo@hotmail.com

C2018 by Anais Brasileiros de Dermatologia routine consultation with the ophthalmologist, which was growing quickly for about 1 year. The lesion was brown, had irregular borders, smooth surface and was elastic, measuring approximately $1.0 \times 0.5 \times 0.4 \mathrm{~cm}$.

The patient had hypertension and diabetes, was using metformin, acetylsalicylic acid, atenolol, losartan, hydrochlorothiazide and simvastatin. She denied alcohol intake or smoking and confirmed frequent exposure to UV radiation. She reported family history of breast cancer and skin cancer.

The lesion was biopsied with the diagnostic hypothesis of melanoma. Histopathology revealed a pigmented, epithelioid malignant neoplasm, consistent with the diagnosis of conjunctival melanoma, confirmed by immunohistochemistry with the positivity for the markers HMB45, Melan A, Ki-67 and protein S-100 in neoplastic cells.

The patient was referred to the specialized center AC Camargo for a more thorough evaluation of the case. Digital retinography and ultrasound biomicroscopy demonstrated a homogeneous well-defined lesion close to the limbus, with medium reflectivity, extending over the cornea and with conjunctival thickening over the peripheral cornea, suggestive of fibrovascular proliferation (Figures 1 and 2).

Treatment was surgical, with the removal of the right eyeball and adjacent tissues. Histopathologic examination of the surgical specimen demonstrated conjunctival melanoma, pT3 staging, with metastases for the palpebral and nasal subconjunctival regions, near the caruncle, associated to conjunctivitis and chronic dacryoad-
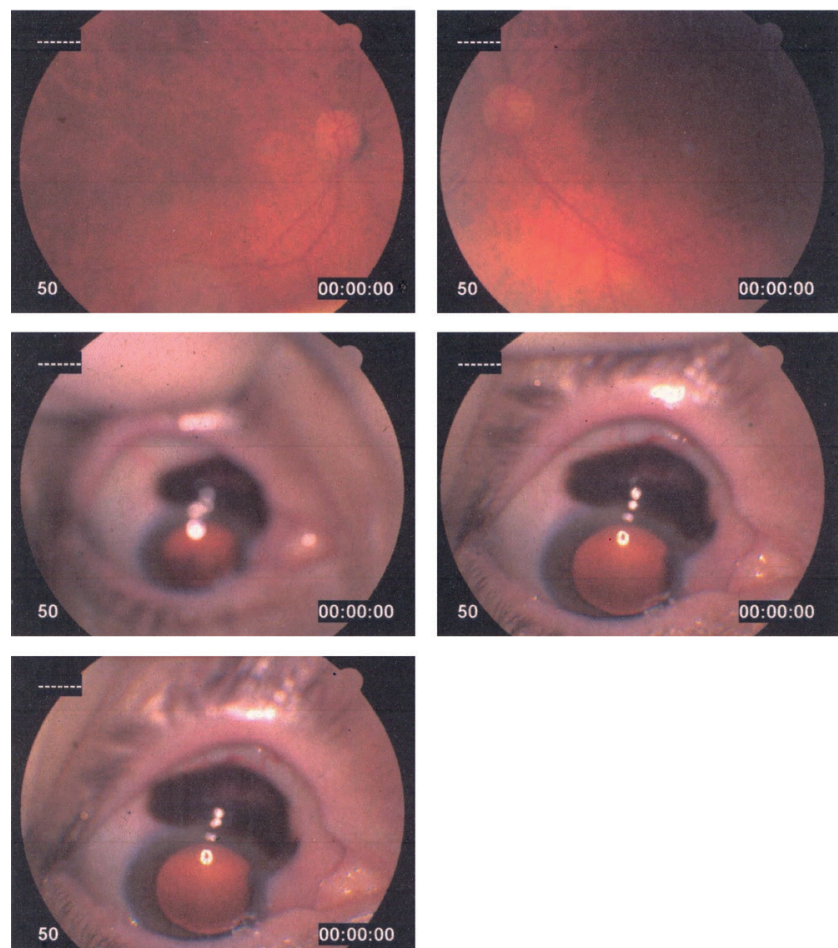

FIGURE 1: Digital retinography: lesion on the nasal conjunctiva of the right eye 

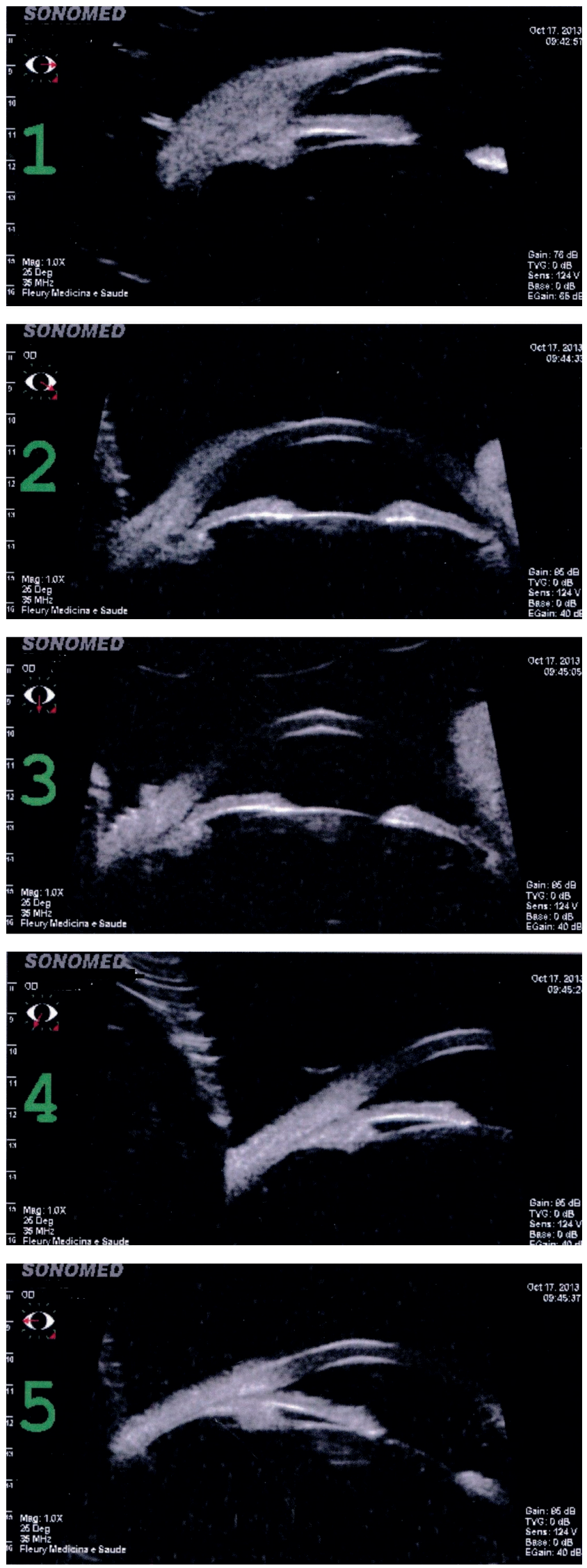

FiguRE 2: Ocular ultrasound: homogeneous lesion near the limbus enitis; the margins were not affected. Systemic investigation did not show signs of distant metastases. She was discharged from hospital and continues being followed up as an outpatient.

According to the literature, the incidence of $\mathrm{OM}$ is of approximately 4 to 6 cases per million people, with uveal melanoma the most common of intraocular melanomas. They are more frequent in men of 50 to 70 years of age and is uncommon in dark-skinned people. Conjunctival melanoma is the least frequent, representing only $2 \%$ of malignant neoplasms in the world and its annual incidence in the Western countries is between 0.2 and 0.5 per 1,000,000 people. It is even rarer in children, with only 29 cases described in the literature. ${ }^{4}$

Approximately half of patients with OM develops metastatic disease within the first five years after treatment. Conjunctival melanoma is more aggressive, with a rate of metastasis of $16 \%$ in five years and $26 \%$ in ten years of follow-up, with a mortality rate of $12 \%$ to $20 \%$ in five years and $30 \%$ in ten years. 5

Metastases of conjunctival melanoma occur through lymphatic and hematogenous spread but they can also directly affect the eyeball, orbit and sinuses. Prognosis is very poor for patients with advanced disease with the mean survival of approximately eight months. ${ }^{5}$

As prevention, any melanocytic lesion in the conjunctiva should be removed. In the case of extensive lesions, these should be closely followed and, if there is any change, intervention should be immediate. Thus, an important role of the dermatologist is to carefully examine not only the skin, but also mucous membranes and, in case a melanocytic lesion is detected in the conjunctival mucosa, advise the patient to see an ophthalmologist for a more thorough examination. This practice avoids mutilating surgeries and saves the patient's life. $\square$

\section{REFERENCES}

1. Amancio CT, Nascimento LFC. Cutaneous melanoma in the state of São Paulo: a spatial approach. An Bras Dermatol. 2014;89:442-6.

2. Rodrigues AAN, Pinheiro TC, Fonseca GC, Martins LM, Tessari MB, Alcadipane FAMC. Melanoma da conjuntiva localizado em pálpebra superior. Rev Fac Ciênc Méd Sorocaba. 2016;18:55-7.

3. Vora GK, Demirci H, Marr B, Mruthyunjava P. Advances in the management of conjunctival melanoma. Surv Ophthalmol. 2017;62:26-42.

4. Cárdenas AO, Wu YCL. Epidemiologia del melanoma ocular (estudio de 11 casos de hospital DR. Rafael Angel Calderon Guardia, entre el periodo 2004 a 2012). Rev Méd Costa Rica. 2014;71:425-30.

5. Maleka A, Åström G, Byström P, Ullenhag GJ. A case report of a patient with metastatic ocular melanoma who experienced a response to treatment with the BRAF inhibitor vemurafenib. BMC Cancer. 2016;16:634.

\footnotetext{
AUTHORS'CONTRIBUTIONS

Marilda Aparecida Milanez Morgado de Abreu (iD) ORCID 0000-0001-9099-6013

Approval of the final version of the manuscript, Effective participation in research orientation, Critical review of the manuscript

Jéssica Priscila Tozo $\quad$ (iD) ORCID 0000-0002-6016-7334

Elaboration and writing of the manuscript, Critical review of the literature

Amanda Kloster Wagner

(iD) ORCID 0000-0001-9458-4729

Elaboration and writing of the manuscript
}

How to cite this article: Morgado de Abreu MAM, Tozo JP, Wagner AK. Conjunctival melanoma. An Bras Dermatol. 2018:93(6):936-7. 